Check for updates

Cite this: RSC Adv., 2019, 9, 14452

Received 25th November 2018 Accepted 5th April 2019

DOI: $10.1039 / \mathrm{c} 8 \mathrm{ra0} 0688 \mathrm{k}$

rsc.li/rsc-advances

\section{An innovative bioresorbable gelatin based 3D scaffold that maintains the stemness of adipose tissue derived stem cells and the plasticity of differentiated neurons}

\author{
Catherine Ann Martin,,$^{\mathrm{ab}}$ Subathra Radhakrishnan, $\dagger^{\text {bf }}$ Sakthivel Nagarajan, ${ }^{\text {a }}$

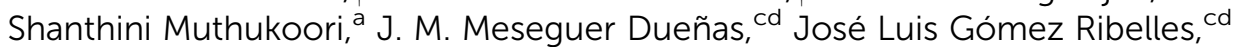 \\ Baddrireddi Subhadra Lakshmi, ${ }^{e}$ Nivethaa E. A. K., ${ }^{a}$ José Antonio Gómez-Tejedor, ${ }^{c d}$ \\ Mettu Srinivas Reddy, ${ }^{b}$ Shanmugaapriya Sellathamby, ${ }^{f}$ Mohamed Rela ${ }^{b}$ \\ and Narayana Kalkura Subbaraya (iD *a
}

\begin{abstract}
Neural tissue engineering aims at producing a simulated environment using a matrix that is suitable to grow specialized neurons/glial cells pertaining to CNS/PNS which replace damaged or lost tissues. The primary goal of this study is to design a compatible scaffold that supports the development of neurallineage cells which aids in neural regeneration. The fabricated, freeze-dried scaffolds consisted of biocompatible, natural and synthetic polymers: gelatin and polyvinyl pyrrolidone. Physiochemical characterization was carried out using Fourier Transform Infrared Spectroscopy (FT-IR) and Scanning Electron Microscopy (SEM) imaging. The 3D construct retains good swelling proficiency and holds the integrated structure that supports cell adhesion and proliferation. The composite of PVP-gelatin is blended in such a way that it matches the mechanical strength of the brain tissue. The cytocompatibility analysis shows that the scaffolds are compatible and permissible for the growth of both stem cells as well as differentiated neurons. A change in the ratios of the scaffold components resulted in varied sizes of pores giving diverse surface morphology, greatly influencing the properties of the neurons. However, there is no change in stem cell properties. Different types of neurons are characterized by the type of gene associated with the neurotransmitter secreted by them. The change in the neuron properties could be attributed to neuroplasticity. The plasticity of the neurons was analyzed using quantitative gene expression studies. It has been observed that the gelatin-rich construct supports the prolonged proliferation of stem cells and multiple neurons along with their plasticity.
\end{abstract}

\section{Introduction}

Neurological Disorders (ND) are diseases that impair the central nervous system and the peripheral nervous system. NDs are caused due to multiple factors such as trauma, neuroinfections, autoimmune diseases, degeneration or loss of functional

\footnotetext{
${ }^{a}$ Crystal Growth Centre, Anna University, Chennai, India. E-mail: kalkura@yahoo. com; kalkurasn@annauniv.edu

${ }^{b}$ National Foundation for Liver Research, Global Hospitals \& Health City, Chennai, India

${ }^{c}$ Center for Biomaterials and Tissue Engineering (CBIT), Universitat Politècnica de València, Camino de Vera s/n., 46022, Valencia, Spain

${ }^{d}$ Biomedical Research Networking Center in Bioengineering, Biomaterials and Nanomedicine (CIBER-BBN), Spain

${ }^{e}$ Department of Biotechnology, Anna University, Chennai, India

${ }^{f}$ Department of Biomedicine, Bharathidasan University, India

$\dagger$ Authors contributed equally to this study.
}

neurons and environmental factors. NDs weaken the structure and function of the nervous system leading to diseased conditions such as Alzheimer's, Parkinson's, dementia, migraine, stroke and multiple sclerosis., ${ }^{\mathbf{1} 2}$ Current therapies for NDs with only chemotherapeutic drugs are ineffective though they provide temporary symptomatic relief. Moreover, progression of the disease towards the end stage cannot be controlled and only palliative therapy could be given., ${ }^{3,4}$ If this condition prevails without unconventional therapeutics it is feared that the number may be tripled by the year 2050 . Hence neurosurgeons and neuroscientists opt for better tissue replacement therapies or cellular therapies. ${ }^{5}$

Cell-based therapies for ND's use stem cells from different sources such as Bone Marrow Stem Cells (BMSCs), Adipose Tissue Stem Cells (ADSCs), Umbilical cord Stem Cells (UCSCs), Embryonic Stem Cells (ESCs), and induced Pluripotent Stem Cells (iPSCs). They are being studied for their potential to be 
used as therapeutic agents to treat NDs. ${ }^{6,7}$ Cells could be administered via various routes like intravenous injection/ intracerebral/intraputaminal/substantia nigra implantation or even directly through vertebral artery. ${ }^{8}$ The anatomical complexity of CNS and PNS makes the appropriate lodging of the cells more difficult. The lodged cells encounter a diseased environment where there is a lack of neurotrophic factors. ${ }^{9}$ Although early experiments were found to be promising, the major challenge lies in the integrity of administered cells with the existing neural network. The recurrent NDs could cause huge damage to the administered therapeutic cells and there is a limited scope of protracted proliferation which is much needed to pacify the degenerative tissues. ${ }^{\mathbf{1 0 - 1 2}}$ Hence, the current therapeutics must focus on providing a comfortable, sustained, micro-environment which supports the neural regeneration with prolonged proliferation and neuroplasticity maintenance. ${ }^{\mathbf{1 3}}$

The need for structural integrity, functionality, mechanical gradients and elasticity has led to the development of various biomaterials for neural tissue engineering. ${ }^{14}$ Poly vinyl pyrrolidone PVP, is a hydrophilic, biocompatible and temperature resistant inert polymer, widely used as a vitreous humor substitute and blood plasma expander which can be stabilized by cross linking. ${ }^{15-17}$ Gelatin obtained due to the hydrolysis of collagen, is biocompatible, biodegradable and a FDA approved material that supports cell adhesion via RGD sequence. ${ }^{18,19}$ Gelatin and PVP have been used for the regeneration of various types of tissues that include islet cells, osteoblasts, bone grafting and tissues for skin replacement. ${ }^{2021}$ Though gelatin (Gel) and PVP have not been used for neural regeneration so far, in the present work effort has been made to synthesize a simple, cost effective composite. The composite would support the growth of stem cells to show that the scaffolds support prolonged and protracted culture and also maintain the plasticity of neural cells, while supporting their proliferation.

\section{Materials \& methods}

\subsection{Materials}

The materials used in this study comprise polymers and other chemicals which include gelatin Type B (Merck), polyvinyl pyrrolidone (PVP) (MW - 40 000) (Merck) and glutaraldehyde (Sigma) of $99 \%$ purity for the fabrication of the biomaterial, using double distilled water. The chemicals for cell culture include Dulbecco's Modified Eagle's Medium (DMEM) (Gibco), Dulbecco's Phosphate Buffered Saline (DPBS) cell culture grade, antibiotic-antimycotic (Invitrogen), Fetal Bovine Serum (FBS) (Invitrogen), basic fibroblast growth factor (bFGF) (Invitrogen), paraformaldehyde (Sigma), Triton X-100 (Sigma) and bovine serum albumin (Sigma). All the reactions were carried out using Millipore grade water for cell culture.

\subsection{Scaffold fabrication}

Gelatin and polyvinyl pyrrolidone (PVP) were dissolved in water. PVP and gelatin were taken such that the weight ratio was $1: 1$, 1:2 and 1:4 (PVP concentration kept as constant). The solutions were mixed with constant stirring and poured in a polypropylene Petri dish (Tarsons), (diameter $-9.2 \mathrm{~cm}$, thickness $-1.2 \mathrm{~cm}$ ) was allowed to gelate overnight at $25^{\circ} \mathrm{C}$, which was followed by incubation at $-20{ }^{\circ} \mathrm{C}$ for $12 \mathrm{~h}$. The scaffold after incubation was lyophilized at $-110{ }^{\circ} \mathrm{C}$ and pressure of -0.002 mbar for 6 h. $^{22}$ The samples containing PVP and gelatin (PVP : gelatin) in different ratios $1: 1,1: 2$ and $1: 4$ will be referred to as PG11, PG12 and PG14, respectively. The scaffolds fabricated were cross-linked using $10 \mathrm{ml}$ of $0.4 \%$ glutaraldehyde (Sigma) overnight and rinsed using deionized water to remove the traces of glutaraldehyde present in the scaffold. The absence of glutaraldehyde was confirmed using FTIR. The scaffolds were pre frozen $\left(-20{ }^{\circ} \mathrm{C}\right.$ for $\left.12 \mathrm{~h}\right)$ and lyophilized as mentioned afore.

\subsection{Material characterization}

2.3.1 Scanning electron microscopy (SEM). The surface morphology of PG11, PG12 and PG14 scaffolds were studied using SEM (Carl Zeiss MA15/EVO 18) at an accelerated voltage of $15 \mathrm{keV}$. The scaffold was coated with gold using a sputter coater (Quorum). The SEM micrographs of the scaffolds with cells were captured at $5^{\text {th }}$ day after seeding $5 \times 10^{4}$ cells onto the surface of the scaffold. These cells were washed with DPBS and the cells were fixed with $4 \%$ paraformaldehyde. The paraformaldehyde was washed off with deionized water after 4 hours. This cell laden scaffold was lyophilized as mentioned before (2.2), after pre-freezing. Since porosity is an important feature of the scaffolds which supports the attachment and proliferation of cells, a comparative study was carried out for the obtained SEM micrographs using Image $\mathrm{J}$ software (National Institute of Health, Bethesda, MD, USA).

2.3.2 Fourier transform infrared spectroscopy (FT-IR). The parental compounds gelatin, PVP and the scaffolds with their various concentrations cross-linked with glutaraldehyde was studied using Attenuated Total Reflection FT-IR (ATR-FT-IR). The IR spectra was obtained using Jasco International Co./ Japan Fourier Transform Infrared Spectrometer Model FTIR6300 , over a range of $400-4000 \mathrm{~cm}^{-1}$ at a resolution of $4 \mathrm{~cm}^{-1}$.

2.3.3 Thermo gravimetric analysis (TGA). The thermal degradation of the gelatin-PVP scaffolds PG11, PG12, PG14 were carried out using the 2 star system Mettler Toledo, Columbus, $\mathrm{OH}$, at a steady scanning rate of $10^{\circ} \mathrm{C} \mathrm{min}^{-1}$ under oxygen atmosphere. This was carried out on $5 \mathrm{mg}$ samples in the temperature range of $100-600{ }^{\circ} \mathrm{C}$.

2.3.4 Tensile property. The tensile strength of the scaffolds was carried out using Universal Testing Machine (UTM) at room temperature (UTM, H10KS, Tinius Olsen, UK using the standard of ASTM D638). The samples with dimensions $1 \mathrm{~mm} \times 9 \mathrm{~mm} \times$ $155 \mathrm{~mm}$ was used for the analysis, with a gauge length of $25 \mathrm{~mm}$ at a cross head speed of $10 \mathrm{~mm} \mathrm{~min}{ }^{-1}$. Tensile strength of the scaffolds was expressed in MPa.

2.3.5 Swelling and dissolution. The swelling properties of the PG11, PG12 and PG14 scaffolds were determined to assess the capacity of water absorption and for confirmation of the crosslinking reactions. All the samples were cut into pieces of $11 \mathrm{mg}\left(W_{0}\right)$ and immersed in $2 \mathrm{ml}$ of DMEM complete medium 
with $10 \%$ FBS. It was incubated at $37{ }^{\circ} \mathrm{C}$. The rate of swelling was studied by the uptake of medium as a function of time. The swelling ratio was calculated by measurement of the weight of the dry scaffold and the weight of the scaffold after incubation in the medium. The ratio of swelling was calculated using eqn (1). ${ }^{23}$

$$
\text { Swelling ratio }=\left(\frac{W_{1}-W_{0}}{W_{0}}\right)
$$

where, $W_{0}$ - initial weight of sample, $W_{1}$ - weight of sample after time.

2.3.6 Hemolysis. Hemocompatibility is an important feature of any implantable biomaterial as they first come into contact with the blood and the rupture of erythrocytes at the site of implantation will have a negative effect on the regeneration of cells. The scaffolds were equilibrated in DPBS overnight before the addition of fresh blood. The blood used for the experiment was collected from a donor in an anticoagulant EDTA tube and diluted using DPBS. $20 \mu \mathrm{l}$ of diluted blood was added to the scaffolds and incubated for 20 minutes at $37{ }^{\circ} \mathrm{C}$. The reaction was stopped by the addition of $2 \mathrm{ml}$ of saline and this was allowed to stand for $1 \mathrm{~h}$ at room temperature. The percentage of hemolysis was calculated using the formula. The blood diluted with water served as the positive control (PC) while the blood diluted with DPBS served as a negative control (NC). The tubes were centrifuged at $1800 \mathrm{rpm}$ at room temperature for 10 minutes. The supernatant was collected and the Optical Density (OD) was recorded at $545 \mathrm{~nm} .^{24,25}$ The percentage hemolysis was calculated using the formula:

$$
\begin{aligned}
\% \text { hemolysis } & =[(\mathrm{OD} \text { of material }-\mathrm{OD} \text { of } \mathrm{NC}) /(\mathrm{OD} \text { of } \mathrm{PC} \\
& -\mathrm{OD} \text { of } \mathrm{NC})] \times 100
\end{aligned}
$$

\subsection{Cell culture}

2.4.1 Isolation of stem cells from infrapatellar fat pad. Stem cells were isolated from infrapatellar fat pad (IFP). Samples were collected from patients undergoing knee arthroplasty. IFP collection for basic research purposes was approved by the Institutional Ethics Committee (IEC - HR/2016/MS/004) and Institutional Committee for Stem cell Research (IC-SCR SR/WOS-A/LS-193/2012) of National Foundation for Liver Research. All the procedures were carried out in accordance with National Guidelines for Stem Cell Research-2017, India. Written consent was obtained from patient after proper explanation about experiments and samples were collected in sterile container with DPBS. The IFP (adipose tissue) was minced and digested overnight using $0.075 \%$ collagenase I (PAN Biotech) enzyme. The collagenase digest was then filtered using a $70 \mu \mathrm{m}$ cell strainer (BD Biosciences) and centrifuged. The pellet (stromal vascular Fraction) was plated using DMEM (Gibco), with $10 \%$ (v/v) FBS (Gibco) and $60 \mu \mathrm{g}$ antibiotic-antimycotic (Gibco) (DMEM complete medium) in $58 \mathrm{~cm}^{2}$ sterile Petri dish. When they were $80 \%$ confluent, the cells were trypsinised using $0.25 \%$ trypsin-EDTA (Gibco) and passaged. The cells from passage 2 were used for further experiments. ${ }^{26,27}$ The cells thus isolated from Infrapatellar Fat Pad (IFP) tissue will hence be referred to as ASCs. The expanded ASCs population was divided into two groups, wherein one group was seeded on the scaffold to check the protracted proliferation and the other group was differentiated to neurons in $2 \mathrm{D}$ environment after which they were seeded on the scaffold to check the compatibility and plasticity.

2.4.2 Neural induction. The ASCs from passage 2 were taken and washed with DPBS thrice, further they are treated with $20 \mathrm{ng} \mathrm{ml}^{-1}$ of bFGF in DMEM (serum free medium) which served as the Neural Induction Medium. The cells were exposed to bFGF continuously for 2 weeks after which they were exposed intermittently, every three days. ${ }^{28}$

2.4.3 Characterization of cells - immunocytochemistry. The cells were cultured on a cover slip in $35 \mathrm{~mm}$ Petri dish, washed with DPBS and fixed using $4 \%$ paraformaldehyde at $4{ }^{\circ} \mathrm{C}$ overnight. For the characterization of ASCs, cells from passage 2, day 14 were used. For characterization of differentiated neurons, cells from passage 7 , day 45 were used. They were then washed with DPBS and the cells were permeabilized with the detergent $0.2 \%$ Triton $\mathrm{X}-100$ for 4 minutes followed by DPBS washing. Later, they were exposed to $1 \%$ Bovine Serum Albumin (BSA), blocking buffer for 1 hour at room temperature.

The primary antibodies in the blocking buffer $(1: 200)$ were added and incubated at $4{ }^{\circ} \mathrm{C}$ overnight. This was washed with DPBS for thrice before the addition of appropriate secondary antibodies conjugated with fluorescein isothiocyanate (FITC) in the blocking buffer $(1: 500)$. This was incubated for 2 hours at room temperature in a dark room. ${ }^{29}$ The cells were washed with DPBS and mounted with glycerol mounting medium and viewed under the fluorescence microscope (Leica DM 2500). The antibodies used in the study are from Santa Cruz Biotechnology, Inc. Switzerland and is tabulated in Table 1.

2.4.4 Hematoxylin and eosin staining. A confluent layer of ASCs and differentiated neuronal cells were fixed using 4\% paraformaldehyde and then stained with Mayer's hematoxylin using the standard protocol. Then, the cells were mounted using di- $n$-butylphthalate in xylene solution. ${ }^{30}$

2.4.5 Cell proliferation and viability-MTT assay. The ASCs and neuronal proliferation rate on the porous scaffolds and tissue culture plate (TCP) were evaluated on day 1, 3 and 5 for ASCs and day 5, 7 and 11 for differentiated neuronal cells, using the MTT assay. Initially, the ASCs and differentiated neurons were plated onto the surface of the scaffolds in a 24 well plate at $1 \times 10^{4}$ cells per well. The well without scaffold served as PC and well without cells served as NC. For ASCs on the $1^{\text {st }}, 3^{\text {rd }}$ and $5^{\text {th }}$ day the DMEM medium was discarded, washed thrice with DPBS and $100 \mu \mathrm{L}$ of MTT solution was added. It was incubated for 5 hours in the dark at $37^{\circ} \mathrm{C}$. For differentiated neurons on the $5^{\text {th }}, 7^{\text {th }}$ and $11^{\text {th }}$ day the neuronal induction medium was discarded, washed thrice with DPBS and $100 \mu \mathrm{L}$ of MTT solution was added followed by 5 hours of incubation in the dark at $37{ }^{\circ} \mathrm{C}$. The purple colored formazan crystals formed in the live mitochondria of the cells were detected by dissolving them in $100 \mu \mathrm{L}$ of Iso Propyl Alcohol (IPA) (Merck) per well. The plates were incubated at $37^{\circ} \mathrm{C}$ for 15 minutes prior to absorbance measurements. The optical density (OD) was recorded on 
Table 1 Antibodies used for immunocytochemistry

\begin{tabular}{lll}
\hline Protein & Primary antibody & Secondary antibody \\
\hline Neuron specific enolase (NSE) & Mouse monoclonal antibody & Goat anti-mouse IgG-FITC \\
Neurofilament light (NF-L) & Mouse monoclonal antibody & Goat anti-mouse IgG-FITC \\
Synaptosome associated protein 25 (SNAP25) & Goat polyclonal antibody & Donkey anti-goat IgG-FITC \\
Syntabulin & Goat polyclonal antibody & Donkey anti-goat IgG-FITC \\
Glyceraldehyde-3-phosphate dehydrogenase (GAPDH) & Mouse monoclonal antibody & Goat anti-mouse IgG-FITC \\
CD166 & Goat polyclonal antibody & Donkey anti goat IgG-FITC \\
Endoglin CD105 & Mouse monolonal antibody & Mouse-IgGkBP-FITC \\
Nanog & Goat polyclonal antibody & Donkey anti goat IgG-FITC \\
Nucleostemin & Goat polyclonal antibody & Donkey anti goat IgG-FITC
\end{tabular}

a multi well microplate reader at $570 \mathrm{~nm}$ and normalized to the control OD. ${ }^{31}$

2.4.6 Live/dead assays. The distribution and viability of ASCs and differentiated neurons seeded on the scaffold were studied using AO/PI staining. $10 \mu \mathrm{l}$ of $1 \mathrm{mM}$ acridine orange and $90 \mu \mathrm{l}$ of $1 \mathrm{mM}$ Propidium Iodide (PI) was mixed together and diluted 10 times with DPBS before using for the 3D culture. ${ }^{32}$ The ASCs and differentiated neurons were plated onto the surface of the scaffolds in a 24 well plate at $1 \times 10^{4}$ cells per well. The cells were stained with AO/PI mix at days 21, 23, 25, after seeding to check the viability on protracted culture. The scaffolds were washed with DPBS before staining them with AO/ PI. This was visualized using a fluorescence microscope (Leica DM 2500).

\subsubsection{Real time PCR}

2.4.7.1 RNA isolation from scaffold. RNA Later solution (Sigma-Aldrich) was added to all the scaffolds and incubated before extraction of the RNA. Total RNA was isolated from the scaffold seeded with control ASCs and differentiated neurons using Trizol reagent (Invitrogen). $1 \mathrm{ml}$ of Trizol reagent was added to the $100 \mathrm{mg}$ of PG11, PG12, PG14 and homogenized until it formed a fine paste. The contents were then transferred to a fresh sterile Eppendorf tube. $200 \mu \mathrm{l}$ of chloroform was added and shaken vigorously for 15 seconds and incubated for 2-3 minutes at room temperature, followed by centrifugation at $14000 \mathrm{rpm}$ for 15 minutes at $4{ }^{\circ} \mathrm{C}$. The aqueous layer was collected and $500 \mu \mathrm{l}$ of $100 \%$ IPA was added. It was incubated for 10 minutes at room temperature and then centrifuged at $14000 \mathrm{rpm}$ for 15 minutes at $4{ }^{\circ} \mathrm{C}$. Supernatant was discarded and the pellet thus obtained was washed with $200 \mu \mathrm{l}$ of $75 \%$ of ethanol (Merck). It was then centrifuged at $14000 \mathrm{rpm}$ for 5 minutes at $4{ }^{\circ} \mathrm{C}$ in a cooling centrifuge (RemiCM12). The RNA pellet was dried and suspended in TE buffer. The quantity and quality of the RNA was measured using the bio-photometer (Eppendorf). The purity of the RNA was determined by the A260/280 absorbance ratio $>1.8$.

2.4.7.2 Gene expression analysis by real time-PCR (qPCR). Template complementary DNA was synthesized using the cDNA preparation kit (Thermoscientific, Product codeAB1453A, Verso cDNA Synthesis kit). All real-time PCR reactions were performed using SYBR Green Master Mix (Applied Biosystem, Life technologies) using Light Cycler 96 [Roche].
The final volume for each reaction was $20 \mu \mathrm{L}$, which comprised $10 \mu \mathrm{L}$ of the master mix, $10 \mathrm{mM}$ each of primers set (forward and reverse), $5 \mathrm{ng}$ of cDNA (volume depending upon the concentration) and sterile distilled water (dH2). Each reaction mix was transferred to a single well of a well plate. The plates were centrifuged at $1000 \times g$ for 1 minute to remove any air bubbles which might affect the efficiency of the PCR. A twostep cycling program was used for all the reactions as follows: $95{ }^{\circ} \mathrm{C}$ for 10 minutes and 40 cycles of $95{ }^{\circ} \mathrm{C}$ for 15 seconds and $60{ }^{\circ} \mathrm{C}$ for 60 seconds. The melting curves were checked to confirm the presence of only one amplified product. The relative gene expression of each gene analyzed was normalized to the expression levels of housekeeping genes. All the results were analyzed using Light Cycler 96 SW 1.1. In each analysis, the sample of the lowest expression was assigned the value of 1 and used as a calibrator. All reactions were performed in triplicates and the data were analyzed according to the $\Delta \Delta C_{\mathrm{t}}$ method. The primer sequences used are summarized in Table 2.

\section{Results}

\subsection{Scaffold topological study using scanning electron microscope (SEM)}

The topological morphology specified by SEM micrographs revealed that the PG11 scaffolds have open, and elongated pores measuring $\sim 185 \mu \mathrm{m}$ in diameter, forming a semi Inter Penetrating Network (IPN), enabling cell attachment and free flow of nutrients and signaling molecules. With an increase in the concentration of gelatin, PG12 scaffolds result in the collapse of the IPN structure and formation of heterogenous pores with an average diameter of $150 \mu \mathrm{m}$. At higher concentrations of gelatin, PG14 scaffolds result in the formation of very small pores and non - uniform grooves on the surface, which hypothetically increases the roughness of the surface. As the concentration of gelatin increases from PG11 to PG14, the open porous structures disappear and only small pores with grooves on the surface appear. All these surface modifications aid in the attachment and proliferation of ASCs and differentiated neurons, as shown in Fig. 1A. The SEM micrographs of the ASCs seeded on the scaffolds are shown in Fig. $1 \mathrm{~B}$ and the neuronal lineage cell laden scaffolds are visualized in Fig. 1C. 
Table 2 Oligonucleotide primer sequences used in GPCR with accession numbers

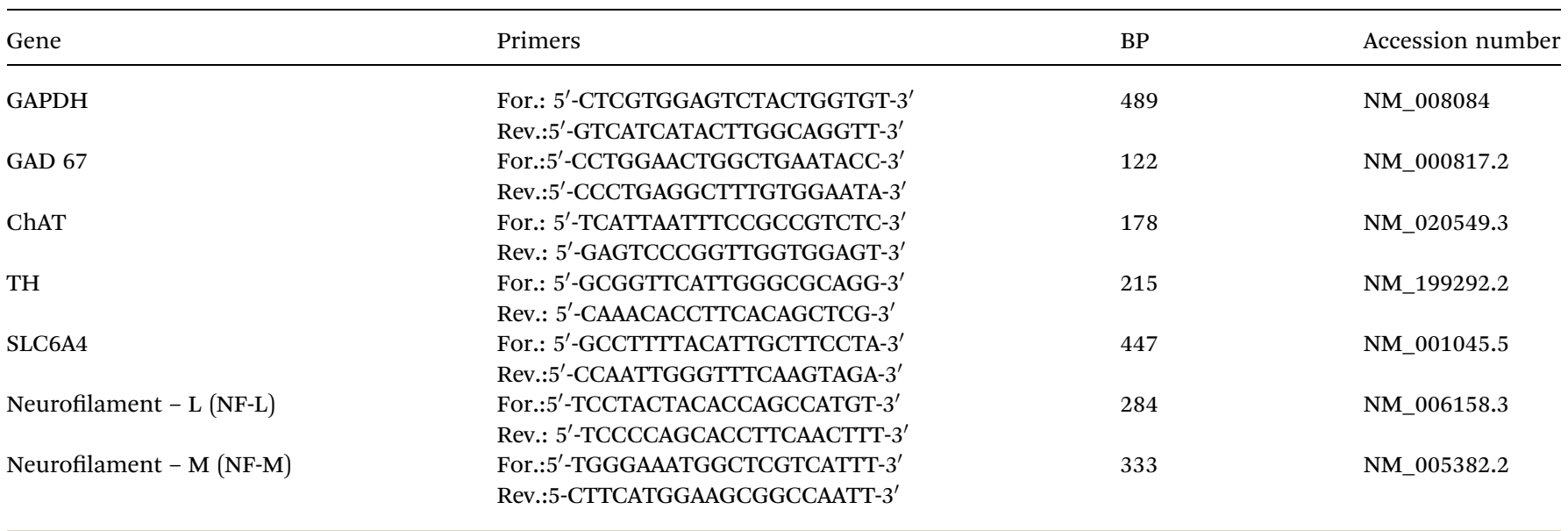

\subsection{Physiochemical study using FT-IR, TGA and DTA}

The FT-IR spectra of the samples were recorded by Attenuated Total Reflectance (ATR) mode as shown in Fig. 2A. The FTIR spectrum showed the peaks characteristic of the polymer constituents, gelatin and PVP. The broad peak at $3284 \mathrm{~cm}^{-1}$ corresponds to the $\mathrm{N}-\mathrm{H}$ stretching. The absence of prominent peaks between $1260-1400 \mathrm{~cm}^{-1}$, indicates that it is not Type I gelatin. The peaks at 1627 and $1543 \mathrm{~cm}^{-1}$ corresponds to carbonyl stretching and amide II, respectively. These functional groups are consistent with parental gelatin, a major constituent of the scaffold. The peak at $1648 \mathrm{~cm}^{-1}$ indicated the presence of carbonyl group in the parental PVP. The interaction of gelatin and PVP is confirmed by the shift from $1648 \mathrm{~cm}^{-1}$ in pure PVP to $1631 \mathrm{~cm}^{-1}$ in the scaffolds. Thus the peaks at 1545 and
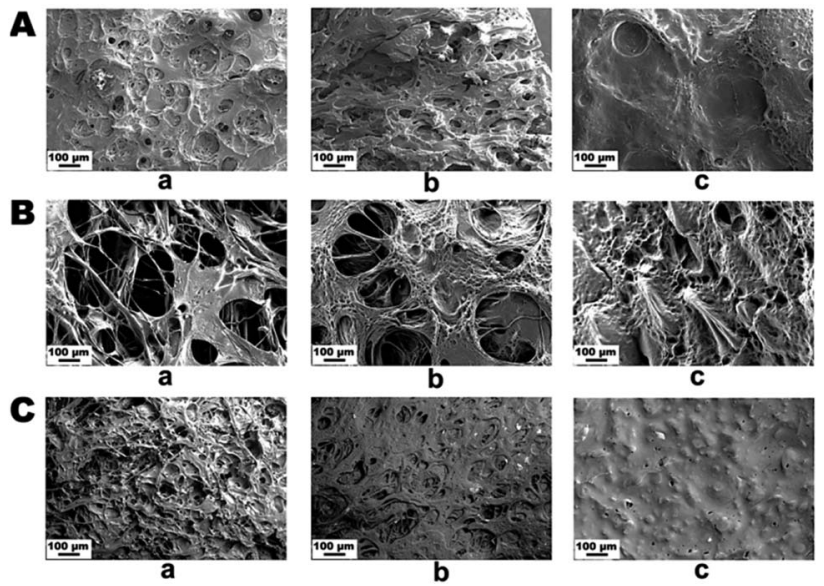

Fig. 1 (A) SEM images of scaffolds without cells (A) PG11 (a), PG12 (b), PG14 (C) showing an interpenetrating porous structure with varying pore sizes. (B) shows SEM images of the adhesion of stem cells on PG11 (a), PG12(b) and PG14 (c) at day 7. (C) showing SEM images of the adhesion of neurons on PG11 (a), PG12 (b) and PG14 (c) at day 11. Both the stem cells and neurons appear to have penetrated into the porous structure of PG11 and PG12 whereas they are only adhered to the surface in PG14 due to the reduced pore size.
$1631 \mathrm{~cm}^{-1}$ shows the presence of gelatin and PVP in the cross linked scaffolds. Absence of the peak at $1711 \mathrm{~cm}^{-1}$ corresponding to glutaraldehyde shows that the sample is devoid of unreacted glutaraldehyde. ${ }^{\mathbf{2 0 , 3 3}}$ The characteristic FTIR spectrum clearly evidences the presence of gelatin and PVP, and confirms crosslinking.

The TGA thermogram of gelatin presents the weight loss due to the evaporation of the water contained in the sample, followed by the main thermal degradation peak, with onset in the weight loss around $240{ }^{\circ} \mathrm{C}$ shown in Fig. 2B. The minimum in the weight derivative appears at $320{ }^{\circ} \mathrm{C}$ Fig. 2C. The major weight loss corresponding to the thermal degradation of PVP
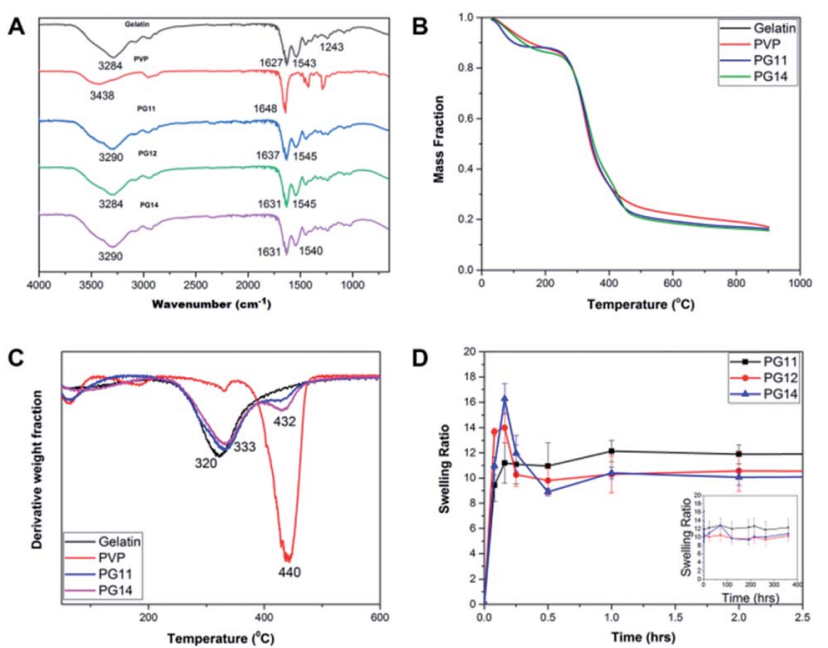

Fig. 2 (A) FT-IR Spectra of PG11, PG12, PG14 with characteristic peaks representing the particular functional groups corresponding to parental Gelatin and PVP. (B) Thermal degradation of both components present in the scaffolds was shown in their TGA thermograms. (C) Derivative Thermal Analysis (DTA) of pure gelatin, pure PVP, PG11 and PG14 confirming the stability and the degradability of the scaffolds. This shows the interaction of the polymers after cross linking. (D) Swelling profile of PG11, PG12 and PG14 over a period of 30 days reveals the stable swelling property and the ability to support the regeneration of tissues. 
takes place at higher temperatures, with a minimum in the weight derivative at $440{ }^{\circ} \mathrm{C}$. This fact allows separating the thermal degradation of both components present in the scaffolds in their TGA thermograms. As shown in Fig. 2B, the weight loss corresponding to the degradation of PVP appears as a shoulder in the high temperature side of the thermal degradation of gelatin, but in the derivative plot it can be observed as a small peak in the same temperature interval in which degradation of pure PVP takes place. On the other hand, their residual weight at high temperatures is quite significant in gelatin at $550{ }^{\circ} \mathrm{C}$ and it corresponds to $23 \%$ of the initial weight of the sample. In the scaffolds, the residual weight is in between that of the pure components as expected and its value can be used to get an estimation of the PVP content in the sample.

The remaining mass of the scaffold sample at $550{ }^{\circ} \mathrm{C}$ in the TGA thermogram $\phi_{550}=M_{550} / M_{0}$, being $M_{0}$ the initial mass of the dry sample calculated at $240{ }^{\circ} \mathrm{C}$ and $M_{550}$ the measured mass in the thermogram at $550{ }^{\circ} \mathrm{C}$, can be expressed as

$$
\phi_{550}=\frac{M_{\mathrm{gel}}}{M_{\mathrm{PVP}}+M_{\mathrm{gel}}} \phi_{550 \mathrm{gel}}+\frac{M_{\mathrm{PVP}}}{M_{\mathrm{PVP}}+M_{\mathrm{gel}}} \phi_{550 \mathrm{PVP}}
$$

where $\phi_{550}$ gel and $\phi_{550} \mathrm{PVP}$ are the remaining mass at $550{ }^{\circ} \mathrm{C}$ measured in the TGA thermograms of pristine gelatin and pristine PVP respectively. From eqn (3) one can obtain the PVP/ gelatin mass ratio in the scaffold

$$
\frac{M_{\mathrm{PVP}}}{M_{\mathrm{gel}}}=\frac{\phi_{550 \mathrm{gel}}-\phi_{550}}{\phi_{550}-\phi_{550 \mathrm{PVP}}}
$$

Interestingly, the PVP content in the scaffolds is not very different in the two compositions, and it is smaller than expected from the PVP/gelatin mass ratio added in the sample preparation. It results to 0.22 and 0.19 in PG11 and PG14 scaffolds, respectively. The small fraction of PVP in the scaffold determined from the residual weight at $550{ }^{\circ} \mathrm{C}$ is in agreement with the small peak observed around $440{ }^{\circ} \mathrm{C}$ in the weight derivative thermogram. ${ }^{20}$

\subsection{Swelling}

Swelling and degradation of the scaffolds depends on the degree of crosslinking and the concentration of the polymers. The swelling ratio of the scaffolds is shown in the Fig. 2D. The scaffolds reach equilibrium and stabilize after an hour which may be due to the dissolution of uncrosslinked polymers, causing an initial decrease. ${ }^{34}$ In PG14, with high gelatin content, the swelling rate reaches its peak by 15 minutes after incubation in the aqueous medium, after which the swelling rate slows down. In contrast, in the first 15 min, PG11 with equal parts of gelatin and PVP showed comparatively less rate of swelling than its two counterparts. The swelling rate of PG12 is intermediary between PG11 and PG14. In this rapid swelling period, the swelling was approximately $100 \%$. The scaffolds are highly stable and have good handling properties throughout the experiments in cell culture media. These scaffolds can be used for tissue engineering where they will be intact until the resultant tissue starts regenerating.
Table 3 Mechanical properties of the scaffolds, where the tensile strength at dry state is higher than that of wet state. The low stiffness helps in cell adhesion and differentiation

\begin{tabular}{lll}
\hline Scaffolds & $\begin{array}{l}\text { Tensile strength (MPa) } \\
\text { in wet state }\end{array}$ & $\begin{array}{l}\text { Tensile strength } \\
(\mathrm{MPa}) \text { in dry state }\end{array}$ \\
\hline PG11 & $0.034+0.001$ & $1.07+0.71$ \\
PG12 & $0.052+0.020$ & $2.37+0.83$ \\
PG14 & $0.028+0.005$ & $1.83+0.12$ \\
\hline
\end{tabular}

\subsection{Mechanical studies}

The mechanical properties of the samples were studied using a thermal mechanical analyser. The mechanical properties of the scaffolds in dry and wet state have been recorded. Table 3 shows the tensile strength of the scaffolds varies from $0.028+$ 0.005 to $0.052+0.020$ in the wet state and $1.071+0.71$ to $2.373+$ 0.83 in the dry state. The increase in the dry state may be due to the presence of PVP which is a plasticizer. ${ }^{20}$ There is no significant difference in the tensile properties of the scaffolds at three different concentrations. Although the scaffolds possess low mechanical properties, they exhibit a good elastic property, which is an advantage to be used in neural tissue engineering. The biocompatibility and cell proliferation studies confirm that the mechanical properties ensured by the scaffold can sustain the mechanical forces caused due to cellular and molecular processes of proliferating stem cells and neurons.

\subsection{Hemolysis}

The scaffolds were subjected to an indirect method of contact of the red blood corpuscles. The rupture of the RBC's resulted in the formation of a red colored supernatant solution similar to the positive control. The tests were conducted in accordance with the ISO 10993, a standard protocol. All the three variations of the synthesized scaffolds showed very low readings almost equal to that of the negative control, proving the hemocompatible nature of the scaffolds. ${ }^{24,25}$

\subsection{Immunocytochemical characterization}

3.6.1 ASCs characterized with lineage specific markers proved they are stem cells with pluripotency markers. ASCs from passage 2, day 14 cultured on individual cover slips in $35 \mathrm{~mm}$ Petri plates were washed and fixed for immunocytochemical analysis. The ASCs were characterized using markers as shown in Table 1. Mesenchymal Stem Cell (MSC) markers, CD105 and CD166 along with embryonic stem cell (ESC) markers Nanog and nucleostemin were expressed in ASCs. The isolated ASCs were MSC with ESC properties (Fig. 3). CD105, (endoline) part of the transforming growth factor- $\beta$ receptor complex is involved in the cell survival and differentiation process and is a cell surface marker of stem cells. ${ }^{35,36}$ CD166 (ALCAM) belonging to immunoglobulin super families, a cell adhesion molecule involved in homotypic and heterotypic interactions of stem cells. This is a type I transmembrane glycoprotein also involved in cell signaling. ${ }^{37}$ Nanog, 

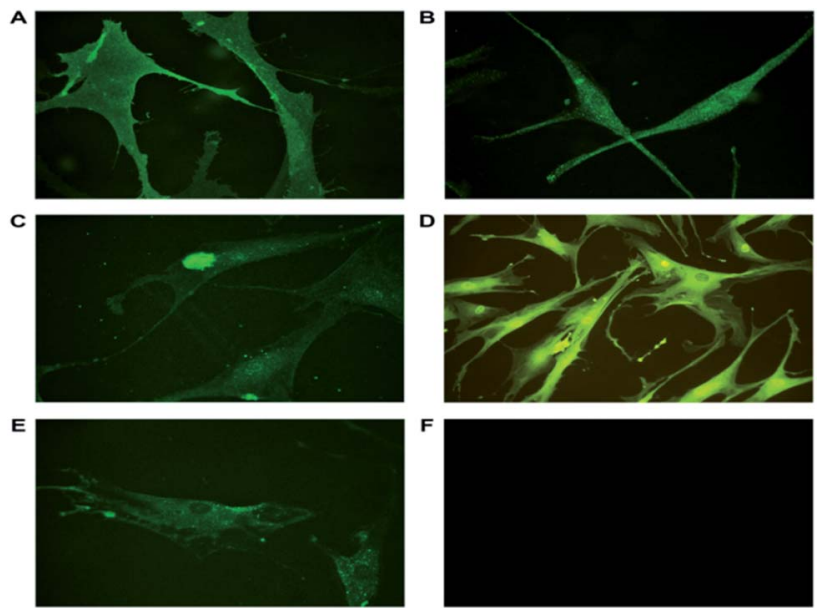

Fig. 3 Representative immunofluorescence images of ASCs stained with specific primary antibodies and secondary antibodies tagged with FITC. (A) CD105, a cell surface marker responsible for cell survival and differentiation is also positively expressed. (B) Nanog, a transcription factor involved in pluripotency expressed in ASCs $(40 \times)$. (C) Nucleostemin, a proliferative marker and cell-cycle regulator localized in nucleus (40×). (D) GAPDH, an endogenous positive control (20×). (E) CD166, involved in cell adhesion and signalling present in plasma membrane and cytoplasm (40 X). (F) Unstained cells. The expression of the markers in the isolated ASCs show they have ESC and MSC properties. The images were taken using Leica DM 2500.

a transcription factor is a key regulator of pluripotency. Nanog along with OCT4 and SOX2 plays a crucial role in maintaining pluripotency. ${ }^{36}$ Nucleostemin, a proliferative marker functions as a cell-cycle regulator and retains the proliferation of stem cells. Glyceraldehyde 3-phosphate dehydrogenase (GAPDH) served as an endogenous positive control. The ASCs have been earlier characterized using FACS analysis to determine the number of cells that maintain the stem cell properties. ${ }^{38}$

3.6.2 ASCs characterized with neuron specific markers proved they are neuronal-lineage cells with functional proteins. ASCs from passage 2 were induced to become neuronal cells through bFGF signaling. Such differentiated neuronal-lineage cells expressed NSE, NF-L, SNAP25, GAP43, syntabulin and nucleostemin (Fig. 4). SNAP-25, synaptosomal associated protein, a presynaptic protein present in the peripheral plasma membrane of neuronal cells. SNAP-25 involved in neurite outgrowth through vesicle fusion was expressed. ${ }^{39}$ The differentiated neurons exhibit Neurofilament Light (NF-L), an intermediate filament also a cytoplasmic structural protein predominantly present in neurite outgrowths of the neuronal cells. NF-L endow the mechanical strength, axonal outgrowth and synaptic plasticity along with NF-H and NF-M. ${ }^{40}$ Neuron Specific Enolase (NSE), gamma enolase, a glycolytic enzyme is a specific marker highly expressed in differentiated neuronal cells. NSE provides neuroprotection against neurodegeneration and aids in neuronal maturation..$^{\mathbf{4 1}}$ During neural development anterograde transportation of active zone components along the neuronal processes is carried out by syntabulin, a part of kinesin adaptor complex aiding in the assembly of pre synaptic
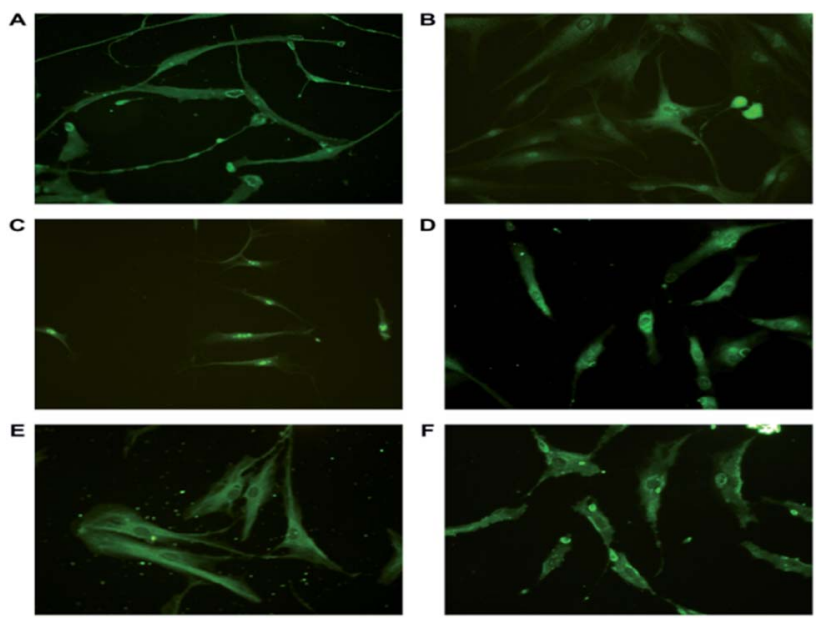

Fig. 4 Representative immunofluorescence images of differentiated neuronal cells stained with antibodies tagged with FITC against (A) NFL, involved in neurite outgrowth and synaptic plasticity present in the filaments. NSE, glycolytic enzyme expressed in differentiated cells and aids in growth and maturation (B). (C) Nucleostemin, a proliferative marker and cell-cycle regulator present only in the nucleus. (D) GAP43, a neuron specific growth associated protein responsible for axonal growth present in the growth cone. (E) Syntabulin, a anterograde transporter protein helps in the assembly of the pre synaptic complex is found to be expressed in periphery of the nucleus (F) SNAP25 , involved in neurite outgrowth, present in the growth cone. The expression of the markers prove the differentiation of the ASCs to neuronal lineage cells. The images were taken at a magnification of $20 \times$ (Nikon)

complex is also expressed in neuronal cells. ${ }^{42}$ Nucleostemin, a proliferative marker is a characteristic feature of neural stem cells and neuroprogenitor cells. The expression of the proliferative marker diminishes as the cells terminally differentiate. This is a dynamic GTPase protein expressed in the nucleoli of the stem cells and neuronal cells.

\subsection{Cell proliferation and viability}

To evaluate the cell adhesion and proliferation MTT assay was performed. As shown in the Fig. 6A, > 95\% of viability and growth of IFPCs seeded on the scaffold was observed at PG11, 12 and 14 on day 1,3 , and 5 . There was no significant change observed in the proliferation pattern of ASCs. Unlike ASCs, the differentiated neuronal cells when grown in different ratios of gelatin and PVP exhibited different growth profiles. The proliferation percentage was also observed to be less than ASCs as shown in Fig. 6B. It was observed that the cells exhibited prominent proliferative percentages at PG11 on day 5 and significantly less proliferation was seen at PG12 on day 11. The scaffold remains relatively stable throughout the experiment supporting the proliferation of both the cell types. Live/dead assay using AO/PI was also performed to analyze the biocompatibility of the Gel-PVP scaffolds. ASCs and differentiated neurons were seeded on the surface of all the variants of the scaffold and maintained for 25 days. The green fluorescent staining showed that most ASCs and differentiated neurons 

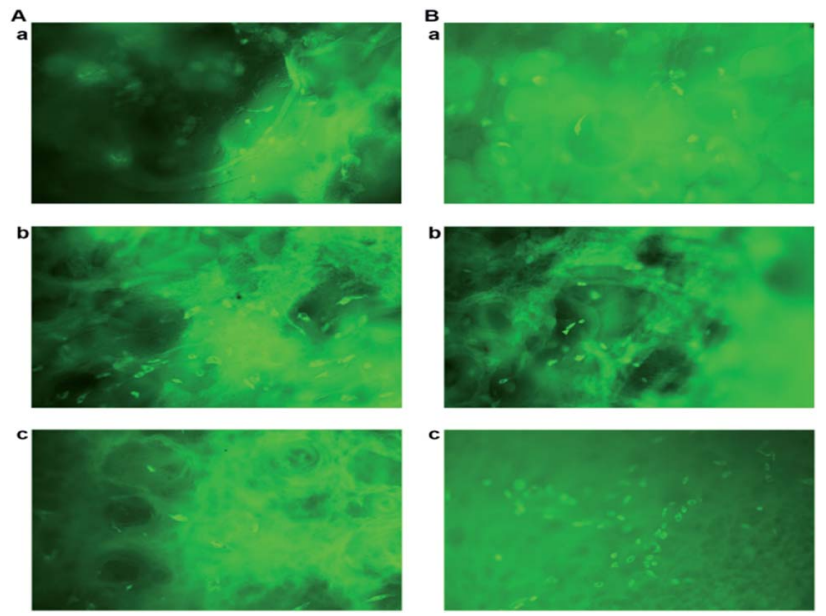

Fig. 5 (A) AO/PI staining of neuronal cells on (a) PG11, (b) PG12 and (c) PG14 on day 11. (B) AO/PI staining of stem cells on (a) PG11, (b) PG12 and (c) PG14 on day 5. The images show that the cells are stained with green due to the binding of acridine orange to the nucleic acid of live cells. Penetration of cells into the 3D matrix is also observed. The images were taken at a magnification of $20 \times$ using Leica DM 2500.

cultured on the scaffolds in prolonged period were live cells as they are only permeable to AO. We observed that both types of cells seeded on the surface were grown in all layers of the scaffold, which implies that the cells were able to penetrate through the open porous and semi IPN structures.

\subsection{Quantitative expression analysis using qPCR revealed the cell -specific markers expressed in ASCs and differentiated neurons}

ASCs seeded on the scaffold were analyzed for MSC markers to validate themselves as stem cells with proliferative marker. ASCs positively expressed CD44, CD166 and nucleostemin (Fig. 5A). On scaffold the stem cells remains intact with good proliferation capacity. Similarly, differentiated neurons seeded on the scaffold were evaluated for neuron-specific markers. The neurofilament light and medium chain were positively expressed in differentiated neurons seeded on all variants of the
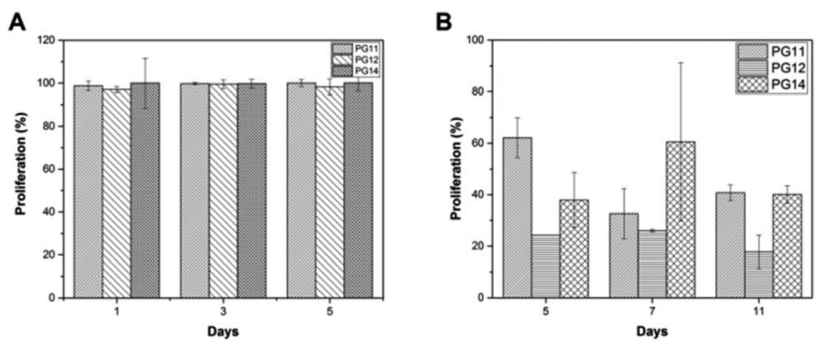

Fig. 6 (A) MTT assay showing stem cell proliferation on PG11, PG12, PG14 on day 1,3 and 5 . There is $>95 \%$ of proliferation in all the scaffolds. (B) MTT assay showing the neuronal cell proliferation on PG11, PG12, PG14 on day 5, 7 and 11. There is no significant proliferation.
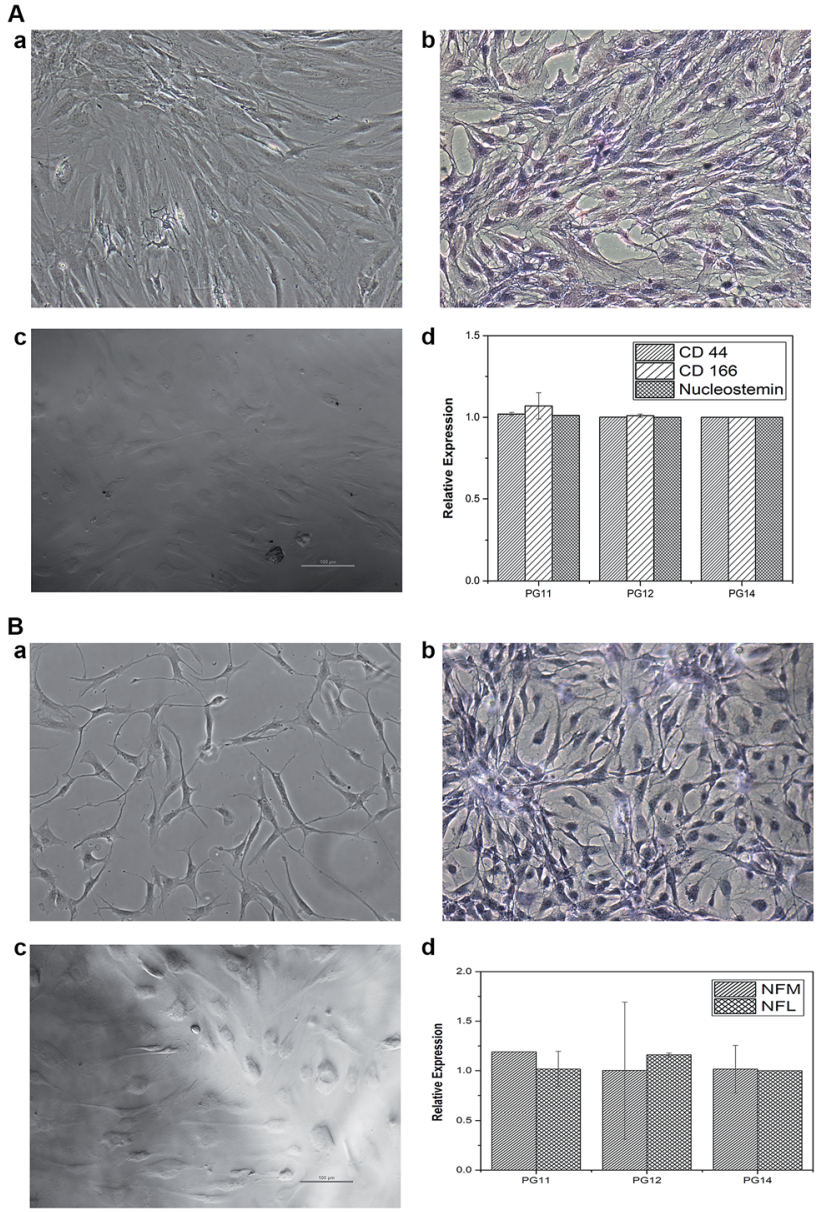

d

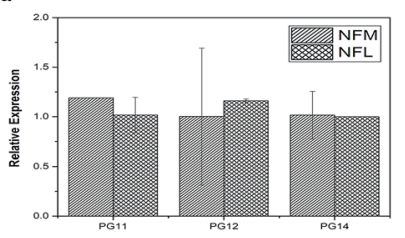

Fig. 7 (A) (a) Represents the phase contrast microscope images of stem cells on Tissue culture plate (TCP) (b) represents the H\&E staining of stem cells in TCP (c) represents the phase contrast microscope images of stem cells on the 3D construct (d) represents the qRT-PCR graph of the gene expression of the stem cell cultured on scaffolds (specific markers CD44, CD166 and nucleostemin). (B) (a) represents the phase contrast microscope image of differentiated neurons in TCP (b) represents the H\&E staining of differentiated neurons in TCP (c) represents the differentiated neurons seeded on the 3D construct (d) represents the qRT-PCR graph of the gene expression of the differentiated neurons grown on scaffolds (specific markers NFM and NFL).

scaffold, validates that they were not dedifferentiated (Fig. 5B). In addition to characterize the types of neurons, gene associated with production of neurotransmitters were also analyzed. PG11 having semi IPN structure highly supports the TH expressing neurons whereas GAD67 expressing neurons is completely absent. PG12 and PG14 showed the same pattern of neurons cultured on these scaffolds and expressed all the genes associated with neurotransmitters tested TH, SLC6A4, GAD67 and ChAT (Fig. 8). Positive expression of these genes at variants of scaffold at the mRNA level validates that the transdifferentiation of MSCs towards a neural-lineage remains intact in 3D matrix too. This also evidences the fact that the scaffolds maintain the neuroplasticity of the neurons seeded on them, an important aspect of neural tissue engineering. 


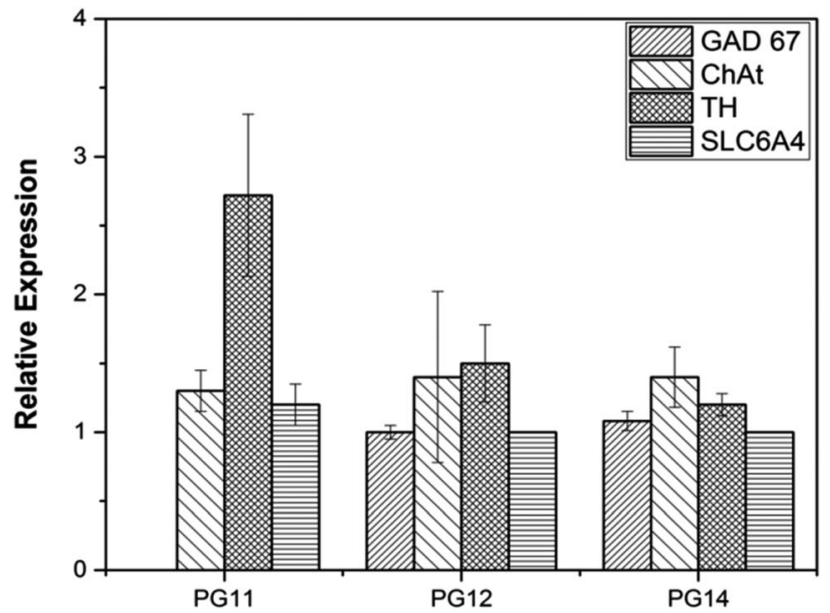

Fig. 8 The quantitative gene expression of protein markers associated with neuro transmitters (TH, GAD67, ChAT and SLC6A4) was performed using real time PCR (qRT-PCR). The differential expression of the genes may be associated with the varying mechanical strength and pore size which reflects on the plasticity of the neuronal cells.

\section{Discussion}

Neural tissue regeneration is a challenging field of tissue engineering and bio-fabrication due to its unique ECM with a delicate mechanical strength. The synthesis of a 3D matrix which mimics the structural integrity of the brain is much more complex. ${ }^{43,44}$ The freeze drying technique allows us to obtain an intricate microporous structure using a wide range of natural and synthetic polymers. ${ }^{44}$ The complex pore morphology not only helps in cell attachment and proliferation but also helps in differentiation. ${ }^{45}$ MSCs are easy available, multipotent, expandable and capable of three germ layer differentiation. MSCs along with a 3D matrix is a suitable material and holds great promise in soft tissue regeneration. Tu X. et al., combined 3D printing technology and freeze drying to produce a porous scaffold using gelatin and polyethylene glycol diacrylate for the proliferation and differentiation of neuroprogenitor cells. ${ }^{46}$ They concluded that the porous gelatin structure provides cues for conduction of neural impulse and reported the advantage of using gelatin in the composite. In vitro mesenchymal stem cell response was studied in PVP modified bioactive glass fibers as tissue constructs. Hatcher BM (2003), observed that the PVP led to stearic stabilization and enhanced shelf-life of the construct, along with enhanced control of the rheological property. The advantage of porosity and enhanced shelf life of the construct in cell proliferation, adhesion and differentiation has been reported. ${ }^{47}$ But differentiating stem cells to neurons in $3 \mathrm{D}$ construct itself is practically tough. Hence in this study we isolated stem cells from Infrapatellar Fat Pad (IFP) cells and expanded in vitro (primary cells). The expanded ASCs population was divided into two groups, wherein one group was seeded on the scaffold to check the protracted proliferation and the other group was differentiated to neurons in 2D environment after which they were seeded on the scaffold to check the compatibility and plasticity.
The present study involves the synthesis of a scaffold with optimal biocompatibility and mechanical properties comprising of synthetic PVP and naturally occurring gelatin. The synthetic materials do not take an active part in cellular adhesion and interactions although they can be produced in large numbers and are flexible to tuning of biophysical properties. At the same time, disordered random coil structure of gelatin obtained from collagen used in this study has linear RGD (Arg-Gly-Asp) sequences which acts as a cell adhesive motif. ${ }^{48}$ The presence of divalent ions in the culture medium aids the attachment of cells to gelatin based scaffold through many integrins primarily of, $\alpha 5 \beta 1$ and $\alpha_{\mathrm{v}} \beta 3 .^{48,49}$ In our effort to produce a 3D matrix for neural tissue engineering, the freeze dried composites scaffolds with varying porosity, as visualized in SEM micrographs were produced. FT-IR-ATR, study of GelPVP blended composite reveals the presence of peaks at 1545 and $1631 \mathrm{~cm}^{-1}$ represents both the components (Fig. 2A). Thermal analysis (Fig. 2B and C) revealed the degradation pattern of both the components. This implies that the composite has perfect blending without the traces of glutaraldehyde which supports cell adhesion, proliferation and differentiation. At lower concentrations pore sizes of $185 \mu \mathrm{m}$ to 150 $\mu \mathrm{m}$ were observed whereas at higher concentrations, formation of groove like structures were seen on the surface which plays a major role in the determination of the types of neurons, since porosity as a physical cue for their transformation. In addition, porosity facilitates cell adhesion, free flow of nutrients, and availability of growth factors and excretion of waste metabolites. ${ }^{50,51}$ The degradation rate of the scaffold is considered as an important attribute for the selection condition of implantable biodegradable scaffolds. The synthesized scaffold remained intact for over a period of 30 days (Fig. 2D) which may be due to the presence of PVP, a temperature resistant stabilizer. ${ }^{47}$ Eventually, the implanted tissue uses this period for a smooth transition to acquire a natural tissue. The long lasting and slow degradation of the synthesized scaffolds is witnessed in the swelling test done using DMEM culture medium at $37^{\circ} \mathrm{C}$. While preparing a neural construct, much attention needs to be given to their tensile properties which impose mechanical forces on the cells, seeded on the construct. The present freeze dried GelPVP construct in all the variants, showed reduced stiffness and tensile properties, varying from 0.05-0.02 MPa (Table 3) which enables high proliferation when implanted in vivo. ${ }^{51}$ Further assessment with cellular attachment, proliferation and gene expression analysis in vitro could be carried out on such a biophysically adequate scaffold.

The ASCs isolated were analyzed for both MSCs (CD166, CD44 and CD105) and ESCs markers (Nanog and nucleostemin). Expression of these stem cell associated proteins in the exact localization revealed that the isolated ASCs were MSCs of mesodermal origin. ${ }^{30}$ At P2 d 14 the ASCs exhibit stemness (Fig. 3 and 5A) and they are subjected to neural induction with a known inducer bFGF. ${ }^{33}$ At P7 day 45 the ASCs are differentiated to neurons showed neurite out growth. The characterization of the resultant cells showed that they positively express the pan-neural proteins NSE, NF-M and NF-L. ${ }^{52}$ The presence of nucleostemin, a putative GTPase and a proliferative marker 
existing in nucleus (Fig. 6c) indicates that neural -lineage cells are still capable of proliferation and they are not postmitotic. ${ }^{53,54}$ Formation of neuronal processes, the activation of anterograde transport of mitochondria, and vesicle fusion in the growth cone have been proven by the presence of GAP43, syntabulin and SNAP 25 (Fig. 4 and 5B).$^{55-58}$ Such characterized ASCs and neuronal cells were seeded and the proliferation was analyzed using MTT. A steady highly proliferative pattern is seen with the ASCs. $>95 \%$ of cells are viable and confirming that the composite supports cell attachment and proliferation of ASCs. Fig. 7B represents the fluorescent images of live/dead assay (AO/PI) portraying the viability of the cells. The MTT results of neuronal differentiated cells can be correlated to the qPCR, where the varying concentrations of the scaffolds support different types of neurons. Hence, a different proliferation pattern is seen in the variants of the scaffolds (Fig. 6B). This may be due to the fact that neuronal cells has the ability to change their form and function in response to mild mechanical alterations in the interacting environment. ${ }^{59}$ In addition, Lins LC et al., 2016 stated that the biomechanical stimulus exerted by the scaffold to the cells play a crucial role in the proliferation and differentiation of neuron and glial cells. ${ }^{60}$ In our observation we found that the differentiation to happened in the variants of the scaffold which was confirmed by our qPCR results. PG11 with a tensile strength of $0.034+0.001 \mathrm{MPa}$ having semi IPN structure supports TH expressing neurons where GAD67 expressing neurons is completely absent. PG14 with tensile strength $0.028+0.005 \mathrm{MPa}$ having less porous and grooves bearing scaffold supports a mixture of TH, GAD67, SLC6A4 and ChAT expressing neurons. PG12 with high tensile strength 0.05 $+0.02 \mathrm{MPa}$ facilitates a higher growth of ChAT and $\mathrm{TH}$ expressing neurons. Thus, the developmental plasticity has been explained as a continuous processing which re-models the neuro-synaptic organization on prolonged incubation (24 days in scaffold) in the 3D matrix. This shows that the mechanical properties of the scaffolds are similar to that of brain tissue. ${ }^{61}$ The polymers used in the present study are highly biocompatible and bioresorbable which makes it a potent material that will be used in future for extensive studies. ${ }^{62,63}$ In future, studies would concentrate on augmentation of constructed 3D matrix in direct transdifferentiation of seeded ASCS to neuronal cells. Despite various clinical approaches being made to repair or regenerate neural injury, the complexity and the limitations of the nervous system, still makes it a challenge to researchers and scientists worldwide. Hence, it can be concluded that the synthesized scaffold supports the growth and proliferation of stem cells and neurons. It also aids in maintaining the plasticity of neurons which is an important feature of all neural-lineage cells.

\section{Conclusion}

Synthesizing a sustainable composite matrix system for neural regeneration was the objective of this study. The obtained scaffold was cost-effective, porous with appropriate mechanical strength, cytocompatible and they are biodegradable. The present study confirms that the gelatin-PVP blend supports the cell adhesion, survival and prolonged proliferation of ASCs and differentiated neurons with great efficacy. Further studies are needed to test the ability of the scaffold to transdifferentiate ASCs to neuronal cells directly on it with minimal culture conditions. As of now, the engineered scaffold has the mechanical strength which matches the brain tissue and supports neuroplasticity of the neurons. This 3D culture system could be used for disease modelling, toxicity testing and to study the development of neurons. Animal studies are needed to prove in vivo functionality of the scaffold.

\section{Conflicts of interest}

Authors declare there is no conflict of interest.

\section{Acknowledgements}

Dr SNK is grateful to the Department of Biotechnology (DBT) BCIL/NER-BPMC/2014-1094 and SVAGATA for the financial support rendered. JMMD and JLGR are grateful for the financial support of the Spanish Ministry of Economy and Competitiveness through the MINECO MAT2016-76039-C4-1-R project (including Feder funds). CIBER-BBN is an initiative funded by the VI National R \& D \& I Plan 2008-2011, "IniciativaIngenio 2010", Consolider Program. CIBER actions are financed by the "Instituto de Salud Carlos III" with assistance from the European Regional Development Fund. The authors also thank Department of Science and Technology (DST) - SR/WOS-A/ LS-193/2012, for the financial support rendered for the cell culture experiments. The authors also thank Dr Jayanthi V., Mr Baskar S. S. and Dr Vishnuvardhanan M., for their contribution in this work.

\section{References}

1 World Health Organization, http://www.who.int/features/qa/ 55/en/, accessed May 2016.

2 Psychguides.com, https:/www.psychguides.com/guides/ neurological-problem-symptoms-causes-and-effects/, accessed 2018.

3 J. M. Savitt, V. L. Dawson and T. M. Dawson, Diagnosis and treatment of Parkinson disease: molecules to medicine, $J$. Clin. Invest., 2006, 116, 1744-1754.

4 L. K. Prashanth, S. Fox and W. G. Meissner, l-Dopa-induced dyskinesia-clinical presentation, genetics, and treatment, Int. Rev. Neurobiol., 2011, 98, 31-54.

5 K. Iqbal, S. F. Kazim, S. Bolognin and J. Blanchard, Shifting balance from neurodegeneration to regeneration of the brain: a novel therapeutic approach to Alzheimer's disease and related neurodegenerative conditions, Neural Regener. Res., 2014, 9, 1518-1519.

6 M. F. Lévesque, T. Neuman and M. Rezak, Therapeutic microinjection of autologous adult human neural stem cells and differentiated neurons for Parkinson's disease: five year post-operative outcome, Open Stem Cell J., 2009, 1, 20-29.

7 A. Trounson and M. Pera, Human embryonic stem cells, Fertil. Steril., 2001, 76, 660-661. 
8 C. Palmer, R. Coronel and l. Liste, Treatment of Parkinson's disease using human stem cells, J. Stem Cell Res. Med., 2016, 1, 71-77.

9 J. W. Xie, M. R. MacEwan, A. G. Schwartz and Y. Xia, Electrospun nanofibres for neural tissue engineering, Nanoscale, 2010, 2, 35-44.

10 E. Hedlund, J. Pruszak, T. Lardaro, W. Ludwig, A. Viñuela, K. S. Kim and O. Isacson, Embryonic stem cell-derived Pitx3-enhanced green fluorescent protein midbrain dopamine neurons survive enrichment by fluorescenceactivated cell sorting and function in an animal model of Parkinson's disease, Stem Cells, 2008, 26, 1526-1536.

11 Y. Mine, T. Hayashi, M. Yamada, H. Okana and T. Kawase, Environmental cue-dependent dopaminergic neuronal differentiation and functional effect of grafted neuroepithelial stem cells in parkinsonian brain, Neurosurgery, 2009, 65, 741-753.

12 M. McLeod, M. Hong, K. Mukhida, D. Sadi, R. Ulalia and I. Mendez, Erythropoietin and GDNF enhance ventral mesencephalic fiber outgrowth and capillary proliferation following neural transplantation in a rodent model of Parkinson's disease, Eur. J. Neurosci., 2006, 24, 361-370.

13 B. Li, H. Yamamori, Y. Tatebayashi, B. Shafit-Zagardo, H. Tanimuka, S. Chen, K. Iqbal and I. Grundke-Iqbal, Failure of neuronal maturation in Alzheimer disease dentate gyrus, J. Neuropathol. Exp. Neurol., 2008, 67, 78-84.

14 A. DíazLantada, E. C. Mayola, S. Deschamps, B. Pareja Sánchez, J. P. GarcíaRuíz, H. Alarcón Iniesta, Tissue Engineering Scaffolds for Repairing Soft Tissues, in Microsystems for Enhanced Control of Cell Behavior, Studies in Mechanobiology, Tissue Engineering and Biomaterials, ed. A. Díaz Lantada, Springer, Cham, 2016, vol 18.

15 A. Yasuda, K. Kojima, K. W. Tinsley, H. Yoshioka, Y. Mori and C. A. Vacanti, In vitro culture of chondrocytes in a novel thermoreversible gelation polymer scaffold containing growth factors, Tissue Eng., 2006, 12, 1237-1245.

16 U. M. Subramanian, S. V. Kumar, N. Nagaiah and U. T. Sivagnanam, Fabrication of Polyvinyl AlcoholPolyvinylpyrrolidone Blend Scaffolds via Electrospinning for Tissue Engineering Applications, Int. J. Polym. Mater., 2014, 63(9), 476-485.

17 J. Lim, H. Im and W. K. Lee, Fabrication of porous chitosanpolyvinyl pyrrolidone scaffolds from a quaternary system via phase separation, J. Biomater. Sci., Polym. Ed., 2015, 26(1), 32-41.

18 H. M. Mansour, M. Sohn, A. Al-Ghananeem and P. P. Deluca, Materials for Pharmaceutical Dosage Forms: Molecular Pharmaceutics and Controlled Release Drug Delivery Aspects, Int. J. Mol. Sci., 2010, 11, 3298-3322.

19 S. Levenbergand and R. Langer, Advances in Tissue Engineering, Curr. Top. Dev. Biol., 2004, 61, 113-134.

20 S. Muthyala, R. R. Bhonde and P. D. Nair, Cytocompatibility studies of mouse pancreatic islets on gelatin-PVP semi IPN scaffolds in vitro: potential implication towards pancreatic tissue engineering, Islets, 2010, 2, 357-366.

21 S. Andrada, P. D. Geta, M. Lavinia, C. H. Emil, V. Eugeniu, M. Bogdan, P. Marius and S. I. Cristina, Gelatin-PVP
Hydrogels with Potential Skin Grafts Applications, Key Eng. Mater., 2014, 638, 38-46.

22 Y. Huang, S. Onyeri, M. Siewe, A. Moshfeghian and S. V. Madihally, In vitro characterization of chitosangelatin scaffolds for tissue engineering, Biomaterials, 2005, 26, 7616-7627.

23 L. Ma, C. Gao, Z. Mao, J. Zhou, J. Shen, X. Hu and C. Han, Collagen/chitosan porous scaffolds with improved biostability for skin tissue engineering, Biomaterials, 2003, 24, 4833-4841.

24 M. Andiappan, S. Sundaramoorthy, N. Panda, G. Meiyazhaban, S. B. Winfred, G. Venkataraman and P. Krishna, Electrospun eri silk fibroin scaffold coated with hydroxyapatite for bone tissue engineering applications, Prog. Biomater., 2013, 2, 6, DOI: 10.1186/2194-0517-2-6.

25 Y. Gui-Bo, Z. You-Zhu, W. Shu-Dong, S. De-Bing, D. Zhi-Hui and F. Wei-Guo, Study of the electrospun PLA/silk fibroingelatin composite nanofibrous scaffold for tissue engineering, J. Biomed. Mater. Res., Part A, 2009, 93, 158-163. 26 A. P. Zuk, M. Zhu, P. Ashjian, D. A. De Ugarte, J. Huang, H. Mizuno, Z. C. Alfonso, J. K. Fraser, P. Benhaim and M. H. Hedrick, Human Adipose Tissue Is a Source of Multipotent Stem Cells, Mol. Biol. Cell, 2002, 13, 4279-4295.

27 Y. Cao, Z. Sun, L. Liao, Y. Meng, Q. Han and R. C. Zhao, Human adipose tissue-derived stem cells differentiate into endothelial cells in vitro and improve postnatal neovascularization in vivo, Biochem. Biophys. Res. Commun., 2005, 332, 370-379.

28 H. Yang, Y. Xia, S. Q. Lu, T. W. Soong and Z. W. Feng, Basic Fibroblast Growth Factor-induced Neuronal Differentiation of Mouse Bone Marrow Stromal Cells Requires FGFR-1, MAPK/ERK, and Transcription Factor AP-1, J. Biol. Chem., 2008, 283, 5287-5295.

29 A. O. Trentz, P. S. Hoerstrup, K. L. Sun, L. Bestmann, A. Platz and O. L. Trentz, Osteoblasts response to allogenic and xenogenic solvent dehydrated cancellous bone in vitro, Biomaterials, 2003, 24, 3417-3426.

30 S. B. Arumugam, O. A. Trentz, D. Arikketh, V. Senthinathan, B. Rosario and P. V. Mohandas, Detection of embryonic stem cell markers in adult human adipose tissue-derived stem cells, Indian J. Pathol. Bacteriol., 2011, 54, 501-508.

31 H. Wang, Y. Li, Y. Zuo, J. Li, S. Ma and L. Cheng, Biocompatibility and osteogenesis of biomimetic nanohydroxyapatite/polyamide composite scaffolds for bone tissue engineering, Biomaterials, 2007, 28, 3338-3348.

$32 \mathrm{~S}$. Y. Lee and G. Tae, Formulation and in vitro characterization of an in situ gelable, photo-polymerizable Pluronic hydrogel suitable for injection, J. Controlled Release, 2007, 119, 313-319.

33 T. H. C. Sallesa, C. B. Lombellob and M. A. d'Ávilaa, Electrospinning of Gelatin/Poly (Vinyl Pyrrolidone) Blends from Water/Acetic Acid, Mater. Res., 2015, 18, 509-518.

34 M. G. Raucci, U. D'Amora, A. Ronca, C. Demitri and L. Ambrosio, Bioactivation Routes of Gelatin-Based Scaffolds to Enhance at Nanoscale Level Bone Tissue Regeneration, Front. Bioeng. Biotechnol., 2019, 7, 1-11. 
35 P. Mark, M. Kleinsorge, R. Gaebel, A. L. Cornelia, T. Anita, P. Erik, D. Robert, S. Gustav and M. Nan, Human Mesenchymal Stem Cells Display Reduced Expression of CD105 after Culture in Serum-Free Medium, Stem Cells Int., 2013, 2013, 698076.

36 G. A. Oyler, J. W. Polli, M. C. Wilson and M. L. Billingsley, Developmental expression of the $25-\mathrm{kDa}$ synaptosomalassociated protein (SNAP-25) in rat brain, Proc. Natl. Acad. Sci. U. S. A., 1991, 88, 5247-5251.

37 A. L. Boyer, T. Lee, F. M. Cole, S. E. Johnstone, S. S. Levine, J. P. Zucker, M. G. Guenthe, R. M. Kumar, H. L. Murray, R. G. Jenner, D. K. Gifford, D. A. Melton, R. Jaenisch and R. A. Young, Core Transcriptional Regulatory Circuitryin Human Embryonic Stem Cells, Cell, 2005, 122, 947-956.

38 S. Radhakrishnan, O. A. Trentz, C. A. Martin, M. S. Reddy, M. Rela, M. Chinnarasu, N. Kalkura and S. Sellathamby, Implications of the passages on Infrapatellar fat pad derived Stem cells - can nucleostemin be a prognostic marker of impaired stemness, Mol. Med. Rep., 2019, 215108.

39 Z. S. Xu, L. C. Cork, J. W. Griffin and D. W. Cleveland, Increased expression of neurofilament subunit NF-L produces morphological alterations that resemble the pathology of human motor neuron disease, Cell, 1993, 73, 23-33.

40 C. L. Schengrund and P. J. Marangos, Neuron-Specific Enolase Levels in Primary Cultures of Neurons, J. Neurosci. Res., 1980, 5, 305-311.

41 Q. Su, Q. Cai, C. Gerwin, C. L. Smith and Z. H. Sheng, Syntabulin is a microtubule-associated protein implicated in syntaxin transport in neurons, Nat. Cell Biol., 2004, 6, 941-953.

42 C. Beekman, M. Nichane, S. D. Clercq, M. Maetens, T. Floss, W. Wurst, E. Bellefroid and J. C. Marine, Evolutionarily Conserved Role of Nucleostemin: Controlling Proliferation of Stem/Progenitor Cells during Early Vertebrate Development, Mol. Cell. Biol., 2006, 26, 9291-9301.

43 B. N. Shelke, P. Leed, M. Anderson, R. K. Nagarale, X. M. Ma, $\mathrm{X}$. $\mathrm{Yu}$ and S. G. Kumbar, Neural tissue engineering: nanofiber-hydrogel based composite scaffolds, Polym. Adv. Technol., 2016, 27, 42-51.

44 A. D. Lantada, E. C. Mayola, S. Deschamps, et al., Handbook on Microsystems for Enhanced Control of Cell Behavior: Fundamentals, Design and Manufacturing Strategies, Applications and Challenges, Springer International Publishing, New York city, vol. 1, 2016.

$45 \mathrm{Z}$. Fereshteh, Freeze-drying technologies for 3D scaffold engineering, Functional 3D Tissue Engineering Scaffolds, Materials Technologies and Applications, ed. Y. Deng and J. Kuiper, Wood head Publishing, an imprint of Elsevier, Duxford, United Kingdom, 2018, pp. 151-174.

46 X. Tu, L. Wang, J. Wei, B. Wang, Y. Tang, J. Shi, Z. Zhang and Y. Chen, 3D printed PEGDA microstructures for gelatin scaffold integration and neuron differentiation, Microelectron. Eng., 2016, 158, 30-34.

47 B. M. Hatcher, C. A. Seegert and A. B. Brennan, Polyvinylpyrrolidone modified bioactive glass fibers as tissue constructs: in vitro mesenchymal stem cell response, J. Biomed. Mater. Res., Part A, 2003, 15(66), 840-849.

48 N. Davidenko, C. Schuster, D. V. Bax, R. W. Farndale, S. Hamaia, S. M. Best and R. E. Cameron, Evaluation of cell binding to collagen and gelatin: a study of the effect of 2D and 3D architecture and surface chemistry, J. Mater. Sci.: Mater. Med., 2016, 27, 148, DOI: 10.1007/s10856-0165763-9.

49 M. Takaeichi and T. S. Okada, Roles of magnesium and calcium ions in cell-to-substrate adhesion, Exp. Cell Res., 1972, 74, 51-60.

50 Q. L. Loh and C. Choong, Three-Dimensional Scaffolds for Tissue Engineering Applications: Role of Porosity and Pore Size, Tissue Eng., Part B, 2013, 19, 485-502.

51 D. K. Bishi, S. Mathapati, J. R. Venugopal, S. Guhathakurta, K. M. Cherian, S. Ramakrishnaa and R. S. Verma, Transdifferentiation of human mesenchymal stem cells generates functional hepatospheres on poly(L-lacticacid)co-poly(3-caprolactone)/collagen nanofibrous Scaffolds, J. Mater. Chem. B, 2013, 1, 3972-3984.

52 S. Radhakrishna, O. A. Trentz, V. K. Parthasarathy and S. Sellathamby, Human Adipose Tissue-Derived Stem Cells Differentiate to Neuronal-like Lineage Cells without Specific Induction, Cell Biol., 2017, 6(1), DOI: 10.4172/23249293.1000131.

53 C. Beekman, M. Nichane, S. D. Clercq, M. Maetens, T. Floss, W. Wurst, E. Bellefroid and J. C. Marine, Evolutionarily conserved role of nucleostemin: controlling proliferation of stem/progenitor cells during early vertebrate development, Mol. Cell. Biol., 2006, 26, 9291-9301.

54 J. Nomura, M. Maruyama, M. Katano, H. Kato, J. Zhang, S. Masui, Y. Mizuno, Y. Okazaki, M. Nishimoto and A. Okuda, Differential requirement for nucleostemin in embryonic stem cell and neural stem cell viability, Stem Cells, 2009, 27, 1066-1076.

55 Q. Cai, C. Gerwin and Z. H. Sheng, Syntabulin-mediated anterograde transport of mitochondria along neuronal processes, J. Cell Biol., 2005, 170, 959-969.

56 J. H Skene, R. D Jacobson, G. J. Snipes, C. B. McGuire, J. J. Norden and J. A. Freeman, A protein induced during nerve growth (GAP-43) is a major component of growthcone membranes, Science, 1986, 233, 783-786.

57 I. C. Bark, K. M. Hahn, A. E. Ryabinin and M. C. Wilson, Differential expression of SNAP-25 protein isoforms during divergent vesicle fusion events of neural development, Proc. Natl. Acad. Sci. U. S. A., 1995, 92, 1510-1514.

58 G. A. Oyler, G. A. Higgins, R. A. Hart, E. Battenberg, M. Billingsley, F. E. Bloom and M. C. Wilson, The identification of a novel synaptosomal-associated protein, SNAP-25, differentially expressed by neuronal subpopulations, J. Cell Biol., 1989, 109, 3039-3052.

59 C. A. Shaw, R. A. Lanius and K. V. D. Doel, The origin of synaptic neuroplasticity: crucial molecules ora dynamical cascade?, Brain Res. Rev., 1994, 19, 241-263.

60 L. C. Lins, F. Wianny, S. Livi, I. A. Hidalgo, C. Dehay, J. Duchet-Rumeau and J. F. Gérard, Development of Bioresorbable Hydrophilic-Hydrophobic Electrospun 
Scaffolds for Neural Tissue Engineering, Biomacromolecules, 2016, 17, 3172-3187.

61 B. Kolb and R. Gibb, Brain Plasticity and Behaviour in the Developing Brain, J. Can. Acad. Child Adolesc Psychiatry, 2011, 20(4), 265-276.

62 A. Samanta, K. Merrett, M. Gerasimov and M. Griffith, Ocular applications of bioresorbable polymers - from basic research to clinical trials, Bioresorbable Polymers for Biomedical
Applications: From Fundamentals to Translational Medicine, 2017, pp. 497-523.

63 B. Feng, S. Wang, D. Hu, W. Fu, J. Wu, H. Hong, I. J. Domian, F. Li and J. Liu, Bioresorbable electrospun gelatin/ polycaprolactone nanofibrous membrane as a barrier to prevent cardiac postoperative adhesion, Acta Biomater., 2019, 83, 211-220. 